\title{
Editorial
}

\section{Duncan Guthrie Chair of Genitourinary Medicine}

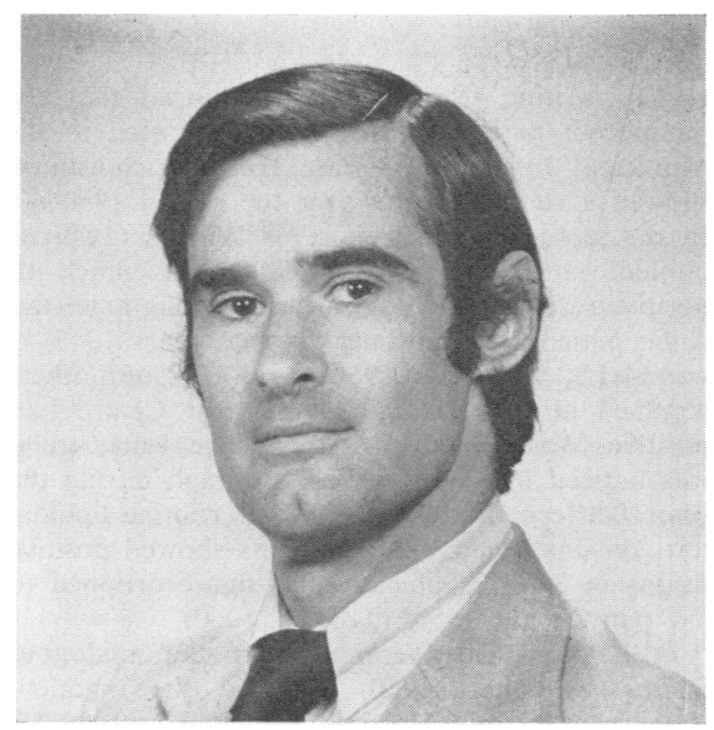

Readers of the British Journal of Venereal Diseases will be aware that a Chair of Genitourinary Medicine has been established in the University of London. While there is still disagreement among those working in the subject in the United Kingdom concerning the name, it is interesting to note that those responsible for creating this chair have chosen to use the term genitourinary medicine.

Dr Michael Adler has been appointed to the newly established Duncan Guthrie Chair of Genitourinary Medicine at the Middlesex Hospital Medical School from 1 January 1979. This is the first chair of genitourinary medicine in the world, and the funds to endow it and the associated department have been raised largely by private contributions and with help from the Department of Health and Social Security. The chair is named in honour of Mr Duncan Guthrie, until recently the director of the National Fund for Research into Crippling Diseases, who played the major role in the raising of the funds.

Dr Adler, who is 38, graduated MB from the Middlesex Hospital Medical School, University of London, in 1965 and proceeded MD in 1977; he became MRCP in 1970. Between 1965 and 1967 he held house appointments at the Middlesex and Central Middlesex Hospitals; he was Senior House Officer in Genitourinary Medicine at the Middlesex Hospital and subsequently Registrar in Cardiothoracic Medicine at the Central Middlesex Hospital until 1970. From 1970 to 1975 he was Lecturer in Epidemiology in the Department of Community Medicine at St. Thomas's Hospital Medical School. In 1975 he was appointed Senior Lecturer in the Department of Community Medicine at the Middlesex Hospital Medical School and Honorary Consultant Physician at the Middlesex Hospital. Since his appointment at the Middlesex Hospital, Dr Adler has been research director of a project on sexually transmitted diseases (STDs), funded by the Medical Research Council, involving the Departments of Venereology and Genitourinary Medicine and of Community Medicine. The research has been concerned with the clinical, epidemiological, and behavioural aspects of STDs.

The Journal offers its best wishes to Dr Adler in establishing his department and will follow its development with interest. 